\title{
RMetS
}

Royal Meteorological Society

\section{Airborne lidar observations in the inflow region of a warm conveyor belt}

\author{
Andreas Schäfler, ${ }^{a \star}$ Andreas Dörnbrack, ${ }^{\mathrm{a}}$ Heini Wernli, ${ }^{\mathrm{b}}$ Christoph Kiemle ${ }^{\mathrm{a}}$ and Stephan \\ Pfahl $^{\mathrm{b}}$ \\ anstitut für Physik der Atmosphäre, Deutsches Zentrum für Luft- und Raumfahrt, Oberpfaffenhofen, Germany \\ ${ }^{\mathrm{b}}$ Institute for Atmospheric and Climate Science, ETH Zurich, Switzerland \\ ${ }^{\star}$ Correspondence to: A. Schäfler, Institut für Physik der Atmosphäre, Deutsches Zentrum für Luft- und Raumfahrt, \\ Oberpfaffenhofen, 82230 Wessling, Germany. E-mail: andreas.schaefler@dlr.de
}

\begin{abstract}
Warm conveyor belts (WCBs) are key flow structures associated with extratropical cyclones. They transport moist air from the cyclone's warm sector poleward and upward close to the tropopause level, leading to the formation of elongated cloud bands, intense latent heating and surface precipitation. In this study a comprehensive dataset of airborne lidar observations of moisture and wind from different campaigns has been investigated with a trajectory-based approach to identify 'lucky encounters' with WCBs. On 19 July 2007, an upstream flight over the Iberian Peninsula during the European THORPEX Regional Campaign (ETReC 2007) in Central Europe intersected two WCBs: one in the upper tropospheric outflow region about 3 days after starting the ascent, and the other one in the boundary layer inflow region over Spain just prior to the strong ascent. Comparison of the lidar humidity measurements with analysis fields from the European Centre for Medium-Range Weather Forecasts (ECMWF) reveals significant positive deviations, equivalent to an overestimation of the modelled humidity, in this low-tropospheric WCB inflow region (of about $1 \mathrm{~g} \mathrm{~kg}^{-1}(14 \%)$ on average and with peak deviations up to $\left.7 \mathrm{~g} \mathrm{~kg}^{-1}\right)$. It is noteworthy that this substantial bias occurs in a potentially dynamically highly relevant air mass that will be subsequently lifted within a WCB to the upper troposphere. A Lagrangian moisture source diagnostic reveals that these large moisture deviations occur within air masses that, according to the ECMWF analyses, are coherently transported from the western Mediterranean towards Spain and experience intense moisture uptake over the Ebro valley. It is suggested that inaccuracies in surface evapotranspiration, horizontal moisture advection, and turbulent vertical transport of moisture in the atmospheric boundary layer potentially contribute to the erroneous lowtropospheric humidity in the inflow region of this particular summertime WCB over Spain in the ECMWF analyses. Copyright (c) 2011 Royal Meteorological Society

Key Words: $\quad$ water vapour; wind; moisture transport; moisture uptake; aircraft observations
\end{abstract}

Received 22 November 2010; Revised 1 March 2011; Accepted 22 March 2011; Published online in Wiley Online Library 14 June 2011

Citation: Schäfler A, Dörnbrack A, Wernli H, Kiemle C, Pfahl S. 2011. Airborne lidar observations in the inflow region of a warm conveyor belt. Q. J. R. Meteorol. Soc. 137: 1257-1272. DOI:10.1002/qj.827

1. Introduction

The Lagrangian conveyor belt model (e.g. Browning et al., 1973; Carlson, 1980) describes the three major airstreams within developing extratropical cyclones. It extended the early Norwegian model of extratropical cyclones that was based upon the concept of frontal zones separating contrasting air masses. Airstreams from the upper troposphere and lower stratosphere (UT/LS) to lower altitudes west of the Northern Hemispheric cyclone generate dry intrusions. 
This airstream can be typically identified as a region of low upper tropospheric humidity and low (or no) cloud cover in water vapour and infrared satellite observations, respectively. Conversely, the airstream exhibiting the strongest ascent and the most intense latent heating associated with precipitation characterizes the warm conveyor belt (WCB). It transports air upward and poleward from the planetary boundary layer $(\mathrm{PBL})$ into the northern mid-latitude upper troposphere within a typical time period of $1-2$ days (Wernli and Davies, 1997). Moist air originating from the warm sector of a developing extratropical cyclone ascends and forms a characteristic elongated band of medium- to high-level clouds. Finally, the westward stream of cold and humid air beneath the WCB and ahead of the warm front is often denoted as the cold conveyor belt.

WCBs with their particularly strong diabatic processes are vitally important as they strongly influence both the evolution of individual extratropical cyclones and the midlatitude general circulation. The poleward transport of sensible and latent heat by WCBs is a key component of the overall atmospheric meridional energy transport in midlatitudes, where the temperature contrast between Pole and Equator is reduced mainly by cyclones and anticyclones due to baroclinic instability. The WCB climatology by Eckhardt et al. (2004) reveals the large contribution of WCBs to mid-latitude precipitation. The intense latent heat release associated with cloud formation and precipitation influences the life cycle of cyclones and thus directly affects atmospheric dynamics. The condensation processes in the coherently ascending airstream lead to the generation of a positive potential vorticity (PV) anomaly in the lower troposphere roughly at the level of maximum latent heating (Wernli and Davies, 1997). This diabatic PV modification can contribute strongly to the intensification of a cyclone (e.g. Kuo et al., 1991; Davis et al., 1993; Rossa et al., 2000). PV is destroyed by diabatic processes above the level of maximum latent heating, which leads to negative PV anomalies in the upper tropospheric WCB outflow region (Wernli, 1997; Pomroy and Thorpe, 2000; Grams et al., 2011). The upper tropospheric modification of PV at the level of the midlatitude jet stream can have a significant impact on the Rossby wave development and associated surface weather further downstream (Massacand et al., 2001; Knippertz and Martin, 2005).

WCB air masses can efficiently be identified with the aid of trajectory calculations and the application of objective selection criteria (Wernli and Davies, 1997; Eckhardt et al., 2004). For the North Atlantic/European region the WCB climatology of Eckhardt et al. (2004) presents average values of the pressure and moisture decrease along WCBs $\left(\Delta p=542 \mathrm{hPa}\right.$ and $\left.\Delta q=9.31 \mathrm{~g} \mathrm{~kg}^{-1}\right)$ as well as of the associated increase of potential temperature $(\Delta \theta=16 \mathrm{~K})$. This highlights the important cross-isentropic component of the transport within WCBs. WCBs in this region occur most frequently during winter, and their ascent typically starts in the western North Atlantic. However, WCBs can originate over the entire North Atlantic and the Mediterranean (see also Ziv et al., 2010).

Additionally, transport by means of WCBs is a primary mechanism for distributing pollution over long distances and to the upper troposphere (e.g. Stohl and Trickl, 1999). Therefore, various airborne measurements during previous field campaigns focused on the chemical footprints of WCBs (Bethan et al., 1998; Vaughan et al., 2003) and on the transport of dust and trace gases (Cooper et al., 2002, 2004). Esler et al. (2003) analysed in situ and sonde data of ozone, humidity and wind that were collected in WCBs of two cyclones over the UK. Given the dynamical relevance of WCBs it is striking that only few observational studies have been made to better characterize these airstreams. In particular, information about their initial moisture content and the latent heating along their ascent is so far almost entirely based upon model data.

During recent years, airborne measurements with lidar of both wind and water vapour were successfully applied to study numerous meteorological phenomena. For example, studies have been made to investigate the PBL water vapour structure (Wakimoto et al., 2006; Kiemle et al., 2007), humidity in the upper troposphere and lower stratosphere (Poberaj et al., 2002), the structure of stratospheric intrusions (Browell et al., 1987; Hoinka and Davies, 2007), and the mesoscale fine structure of extratropical cyclones (Flentje et al., 2005). Flentje et al. (2007) compared analyses of the European Centre for Medium-Range Weather Forecasts (ECMWF) with differential absorption lidar (DIAL) water vapour measurements in the Tropics and Subtropics over the Atlantic Ocean between Europe and Brazil. Kiemle et al. (2007) calculated vertical water vapour flux profiles from a combination of data from a wind and a water vapour lidar. Schäfler et al. (2010) developed a method to determine the horizontal water vapour transport from collocated lidar measurements of wind and humidity in the vicinity of an extratropical cyclone.

This study will describe and apply a method to identify, for the first time, WCB observations within lidar cross-sections measured during various field experiments. Between 2002 and 2008, the Deutsches Zentrum für Luft und Raumfahrt (DLR) research aircraft Falcon participated in seven campaigns where humidity and wind were observed with lidars in different regions over the North Atlantic and Europe. As none of these field experiments focused on WCBs, the analysis performed in this study corresponds to a search for 'lucky WCB encounters'. One of these occurred on 19 July 2007 during the European THORPEX* Regional Campaign (ETReC, 2007) with PBL observations in the inflow of a WCB. The associated cyclone caused exceptionally high amounts of rain over the UK (Prior and Beswick, 2008) and was one event in a series of high-impact weather events in summer 2007 (Blackburn et al., 2008). It was shown that the majority of precipitation was related to large-scale rain generated by the uniform ascent within a WCB. For the analysis of WCBs during this mission, a Lagrangian detection method to identify the exact location of the WCB inflow region will be introduced (section 3). The lidar observations, the structure of the observed WCBs and a comparison of the measurements with ECMWF analysis fields will be presented (section 4). For the moisture in the WCB inflow region we will apply a Lagrangian moisture source diagnostic, which will help pinpoint potential model errors leading to substantial deviations of the model humidity compared to the observations in the WCB inflow region (section 5).

*The Observing System Research and Predictability Experiment (THORPEX) is a 10-year research programme of the World Meteorological Organization (WMO). 


\section{Instruments and dataset}

\subsection{Water vapour lidar}

Deriving tropospheric water vapour profiles by means of the differential absorption method is a ground-based and airborne lidar technique that is well described in the aforementioned literature. Two laser pulses - one at a water vapour absorbing and another at a nonabsorbing wavelength - are successively transmitted into the atmosphere. The difference in the backscattered signals is a measure of the density of water vapour within the illuminated volume. A range-dependent profile is determined by measuring the run time of the signal. To avoid interference by other trace gases the wavelength is chosen at around $935 \mathrm{~nm}$, where water vapour has wellknown and narrow absorption lines. Therefore, the laser system has to fulfil high frequency stability and spectral narrowness.

Installed on an aircraft, the nadir pointing DIAL profiles yield two-dimensional cross-sections through the atmosphere displaying the mixing ratio of water vapour beneath the aircraft. DLR has developed and operated two different water vapour DIAL systems since 2002. The former two-wavelength system was used until 2007. For a detailed description of the system and the measurement accuracy see Poberaj et al. (2002). A major step to observe the whole range of tropospheric water vapour concentrations that vary by three orders of magnitude was made when the new four-wavelength DIAL WALES (Water vapour Lidar Experiment in Space) was completed in 2007. It was designed as an airborne demonstrator for a prospective satellite instrument. The resulting water vapour profile consists of a combination of backscattered signals from three wavelengths tuned to absorption lines sensitive at different humidity concentrations (for a detailed description of the system see Wirth et al., 2009). Note that during the jointly performed campaigns - the Convective and Orographically Induced Precipitation Study (COPS) and ETReC 2007 - the DIAL was operated for the first time at three wavelengths (one online, two offline).

The horizontal spacing of the profiles basically depends on the pulse repetition frequency. However, horizontal and vertical smoothing is applied to reduce statistical errors resulting from instrument noise. Additionally, systematic errors (spectral characteristics and purity of the absorption lines, wavelength stability, and temperature impact on the absorption cross-section) influence the accuracy. To keep the uncertainty below $15 \%$ an evaluation of the data at different spectral purities was applied (see Schäfler et al., 2010). In the present case study, the DIAL data possess a horizontal resolution of $\sim 14 \mathrm{~km}$ (averaged over $60 \mathrm{~s}$ ) and a vertical range resolution of $\sim 350 \mathrm{~m}$. A recent inter-comparison study of different water vapour lidars that were operated during COPS by Bhawar et al. (2011) showed a low systematic error (bias of $-2 \%$ ) for the DIAL WALES.

A further variable observed by the DIAL system is the atmospheric backscatter ratio (BSR) measured at a wavelength of $1064 \mathrm{~nm}$, which is the ratio of the total (particle and molecular) backscatter coefficient and the molecular backscatter coefficient. The resolution of the backscatter data is $15 \mathrm{~m}$ vertically and $10 \mathrm{~s}(2 \mathrm{~km})$ horizontally. Typical values range from 1 in a clean atmosphere to 100 in regions with a high aerosol load.

\subsection{Doppler wind lidar}

The DLR $2 \mu \mathrm{m}$ wind lidar measures the frequency shift between emitted and received signal that results from the optical Doppler effect at the scattering particles and is proportional to the line of sight (LOS) velocity. The horizontal wind field can be determined from the LOS velocity by measuring at different beam angles under the assumption of horizontal homogeneity of the wind field. This is achieved with two rotating refractive wedges that perform a conical step-and-stare scan under an off-nadir angle of $20^{\circ}$ (velocity azimuth display (VAD) technique).

Each profile consists of LOS measurements of one scanner revolution $(\sim 32 \mathrm{~s})$. For a detailed description of the wind vector calculation see Weissmann et al. (2005). The accuracy of the wind measurements is $\sim 0.1 \mathrm{~m} \mathrm{~s}^{-1}$ at high signal-tonoise ratios. The vertical resolution is $100 \mathrm{~m}$. The horizontal resolution is $32 \mathrm{~s}$, which results in a mean horizontal profile distance of $\sim 7.3 \mathrm{~km}$, given an aircraft speed of $\sim 230 \mathrm{~m} \mathrm{~s}^{-1}$.

\subsection{Lidar dataset}

Over the past years the DLR research aircraft Falcon was involved in a multitude of international research campaigns with different scientific objectives. These measurements contribute to our knowledge on the water vapour distribution in the whole troposphere and lower stratosphere and to a better understanding of atmospheric processes. The flight tracks of the aircraft in the considered campaigns are shown in Figure 1. About 230 flight hours from seven research campaigns are taken into account. The actual total lidar observation time is shorter because the systems worked only when the flight level was reached. The spatial distribution of WCBs, in the climatology of Eckhardt et al. (2004), shows that they occur in a latitude belt between $20^{\circ}$ and $75^{\circ} \mathrm{N}$, preferably located on the leading edge of developing or amplifying upper-level troughs. Therefore, we exclude inappropriate flights in geographical regions or during meteorological situations that are unlikely to be associated with a WCB, i.e. in tropical and polar air masses away from baroclinic zones as well as in high-pressure situations.

During six transfer flights to Oklahoma (Kansas, USA) where the International H2O Project (IHOP_2002; Weckwerth et al., 2004) in 2002 took place (black lines in Figure 1) water vapour was observed in the vicinity of the Atlantic wave guide with the aforementioned twowavelength DIAL (Flentje et al., 2005). Tropospheric water vapour was probed on the inbound flights from the Tropical Convection, Cirrus and Nitrogen Oxides Experiment (TROCCINOX; Flentje et al., 2007) and the Stratospheric-Climate links with emphasis on the UT/LS (SCOUT) experiment (Vaughan et al., 2008). Based on the case study by Flentje et al. (2007) we found no evidence that WCB air masses were probed on the TROCCINOX transfer flights from Brazil to Europe.

In summer 2007, during COPS (Wulfmeyer et al., 2008) and ETReC 2007 the DIAL WALES and the wind lidar performed first collocated measurements over Western Europe. In addition to the various local flights over 


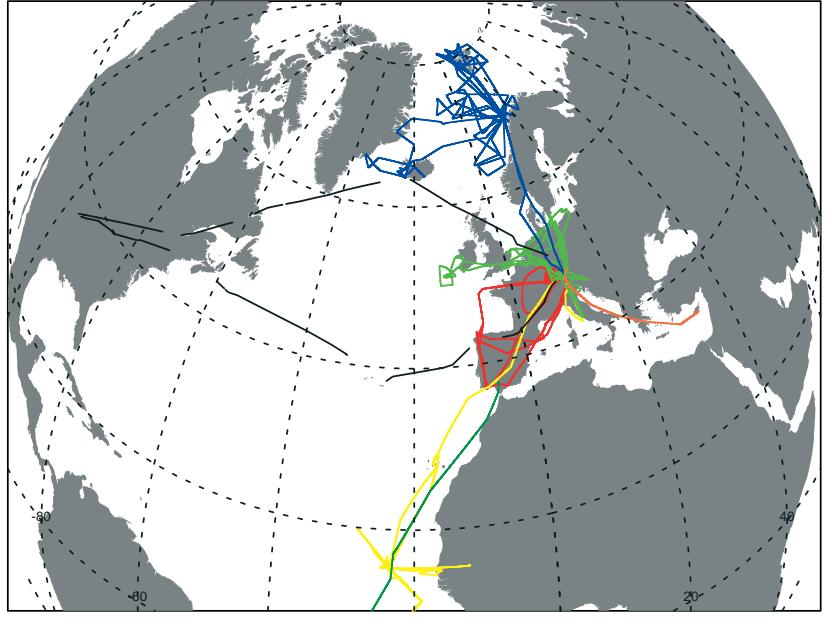

Figure 1. Falcon flight paths of lidar missions considered for the WCB search from 2002 to 2008: IHOP transfer flights in 2002 (black), TROCCINOX transfer in 2004 (dark green), SCOUT transfer in 2005 (orange), COPS/ETReC 2007 in 2007 (red), IPY-THORPEX (blue), SAMUM 2 (yellow) and EUCAARI (light green) in 2008.

southern Germany, elongated flights to upstream regions with airborne observations of the horizontal moisture transport were undertaken during the associated ETReC 2007 campaign (Schäfler et al., 2010).

The IPY-THORPEX campaign which was part of the International Polar Year (IPY) in 2008 aimed at observations of polar lows in the Barents Sea (Wagner et al., 2011). Water vapour was also observed during the second Saharan Mineral Dust Experiment (SAMUM-2) when research flights were carried out from the Cape Verde Islands. IPY-THORPEX and SAMUM-2 have been rejected as both campaigns took place in polar and tropical air masses, respectively, decoupled from the mid-latitudes. During the European integrated project on Aerosol Cloud Climate and Air Quality Interactions (EUCAARI) in 2008 in situ instruments measuring aerosol properties were supported by the DIAL to obtain water vapour and aerosol backscatter information. A persistent blocking anticyclone that influenced central Europe made the occurrence of WCBs very unlikely and therefore the EUCAARI data could not be considered further in this study.

After pre-selection with regard to the meteorology and geographical location we considered the missions of the campaigns IHOP, COPS/ETReC as well as the SCOUT transfer flight to be promising for possible WCB intersections. The ensuing Lagrangian diagnostic to search for WCB encounters is described in section 3 .

\subsection{ECMWF analysis and forecast data}

Model fields from the ECMWF Integrated Forecasting System (IFS) are used to perform comparisons with the observations and to drive the trajectory calculations. In this study, we have used the IFS version with a T799L91 spatial resolution that was operational in 2006. The 799 spectral components correspond to a grid point spacing of approximately $25 \mathrm{~km}$ in the horizontal. The 91 vertical model levels are irregularly distributed from 1000 to $0.1 \mathrm{hPa}$, with a higher density close to the ground. The spectral analysis data have been interpolated to a regular lat-lon grid $\left(0.25^{\circ} / 0.25^{\circ}\right)$. To enhance the temporal resolution in the model fields, ECMWF operational analysis fields (at 0000, 0600, 1200 and 1800 UTC) were supplemented by short-term forecast fields which were treated as 'pseudo-analyses'. Therefore, special forecast runs with 1-hourly output up to $+5 \mathrm{~h}$ were run four times a day.

\section{Description of the methods}

\subsection{Identification of WCB observations}

The aircraft missions that have been selected to search for possible WCB observations (see section 2.3) comprise approximately 52.5 flight hours. For these missions, we identified WCBs by analyzing ensembles of trajectories calculated with the Lagrangian analysis tool LAGRANTO (Wernli and Davies, 1997). Based on 6-hourly ECMWF analyses, trajectories were started every $6 \mathrm{~h}$ during a time period of 6 days ( 4 days before and 1 day after the respective mission) at every model grid point below $850 \mathrm{hPa}$ in an area from $120^{\circ} \mathrm{W}$ to $80^{\circ} \mathrm{E}$ and $10^{\circ} \mathrm{N}$ to $90^{\circ} \mathrm{N}$. The trajectories with an ascent of more than $600 \mathrm{hPa}$ in $48 \mathrm{~h}$ were identified as WCB trajectories (Wernli and Davies, 1997). These trajectories were investigated for intersections with the flight tracks to analyse whether lidar observations were taken in the vicinity of a WCB. Most intersections occurred during IHOP_2002, where four of the six missions showed WCB crossings. An analysis of the intersection time and altitude with respect to the position in the WCB revealed that most WCB parcels were observed in the upper troposphere several hours after the WCB ascent. During COPS and ETReC 2007, the two missions on 19 July and 1 August 2007 (see Schäfler et al., 2010, for details on this mission) offer WCB intersections. The mission on 19 July features a considerable number of observations taken in the lower tropospheric inflow region prior to the ascent of parcels in the WCB. Because these measurements provide key information on the initial moisture field streaming into the WCB, this mission was selected for a detailed case study presented in section 4 .

In order to allow for a precise comparison of the lidar observations with the ECMWF fields, we applied a refined Lagrangian diagnostic for the selected COPS mission on 19 July 2007. LAGRANTO provides information about the evolution of selected meteorological parameters (e.g. pressure, temperature, potential temperature, and potential vorticity) along the trajectory. By starting both forward and backward trajectory calculations from every observation point (given by its geographical coordinates, pressure and time) along the lidar cross-section, it is possible to investigate the material change of these variables. Since hourly fields from short-term forecasts for a 6-day period (0000 UTC 15 July to 0000 UTC 21 July) were available, a sensitivity study on the influence of the temporal resolution of the driving wind fields on the trajectory calculations could be performed, as presented in the Appendix. The results discussed in section 4 will be based on the 3-hourly resolution data, as this time increment is available from operational forecast and analysis fields from the IFS archive. For the moisture uptake diagnostic in section 4.5, 6-hourly fields were used. 


\subsection{Interpolation of model data to the collocated lidar grid and comparison}

Comparing gridded model data with temporally continuous lidar profiles is a method that has been repeatedly used to qualitatively and quantitatively analyse lidar observations of wind and water vapour. In the following, a short description of the interpolation method is given which is analogous to that used by Flentje et al. (2007) and Schäfler et al. (2010).

A bilinear interpolation from the surrounding grid points is performed to project model information onto the lidar profiles, followed by a vertical interpolation of the model profile towards the lidar resolution. The interpolation is performed for every output time of the IFS. The 1-hourly output of the IFS allows the use of linear interpolation in time and a more accurate representation of the model fields at the time of the observation compared to more coarsely resolved data. Different meteorological parameters are displayed along the cross-section to interpret the observations (see, for example, Figure 4).

Analogous to the method presented by Schäfler et al. (2010) the observations of wind and water vapour are interpolated to a collocated grid with a resolution of $100 \mathrm{~m}$ vertically and $30 \mathrm{~s}$ horizontally. The collocated grid defines the starting positions for the calculation of trajectories to investigate which part of the wind and water vapour observations belongs to the WCB. Differences between observed and modelled humidity and wind velocity can be used to verify analysis and forecast fields. As proposed by Flentje et al. (2007) we present absolute and relative deviations that are normalized by the mean value of observations and model data. The bilinear interpolation to the collocated grid is accompanied by a slight reduction of the data coverage. For this reason, all differences between ECMWF and lidar are shown at the original resolution of the wind and water vapour fields (see sections 2.1 and 2.2).

\section{Case study of 19 July 2007}

\subsection{Synoptic overview}

The flight on 19 July 2007 from Faro (Portugal) to Oberpfaffenhofen (Germany) took place between 1110 and 1440 UTC (see flight path in Figure 2(a) and (d)). After flying northward along the western coastline of Spain the aircraft turned eastward crossing Spain south of the Pyrenees, into the Gulf of Lyons before crossing the Alps. Lidar observations of both humidity and wind are available between 1156 and 1314 UTC, i.e. mainly in a W-E oriented curtain along northern Spain (indicated by the solid line in Figure 2).

The weather situation over Western Europe at that time (1200 UTC 19 July, see Figure 2(a) and (d)) is characterized by an upper-level trough with its centre located southwest of the UK. Warm and moist air was advected northeastward ahead of the trough, as confirmed by the high values of the equivalent potential temperature $\left(\theta_{\mathrm{e}}\right)$. The flight path crossed this tongue of high $\theta_{\mathrm{e}}$ air on the way to the Mediterranean. Over Galicia, where the aircraft turned eastward, the flight path intersected a jet maximum at $500 \mathrm{hPa}$ with peak wind speed of about $30 \mathrm{~m} \mathrm{~s}^{-1}$.

The ECMWF analysis taken $12 \mathrm{~h}$ later depicts a jet stream maximum which is embedded in the large trough (Figure 2(b)). The jet streak propagated towards France and cyclogenesis was initiated in the left jet exit region over Brittany. This evolution is visible in the geopotential height field and, especially, in the deformation of the frontal zone (high $\theta_{\mathrm{e}}$ gradient; Figure $\left.2(\mathrm{e})\right)$. Another $12 \mathrm{~h}$ later, at 1200 UTC 20 July, the jet is positioned over France (Figure 2(c)) and the frontal wave intensified as indicated by a significantly decreased geopotential height at $850 \mathrm{hPa}$ (Figure 2(f)). In the course of this development intense convection was triggered by the upper-level anomaly in the unstable air mass over France and southwestern Germany during the night and the following day.

Figure 3 shows a composite of the Moderate Resolution Imaging Spectroradiometer (MODIS) for 19 and 20 July 2007. The satellite imagery at 1150 UTC 19 July 2007 (Figure 3(a)) shows shallow, unorganized cumulus clouds over northwestern Spain but not further to the east in the air associated with high $\theta_{\mathrm{e}}$ values (Figure $2(\mathrm{~d})$ ). On the next day, at 1050 UTC 20 July when the developing cyclone moved to the UK, the satellite picture (Figure 3(b)) shows the occluded part of the frontal system with dense high-level clouds over England and Ireland. Cirrus is fraying out on the northern edge. Below the cirrus shield over western Germany intense convective cells are triggered ahead of the cold front. Over France shallow cumulus formed in the cold air that arrived behind the cold front.

\subsection{Interpretation of wind and water vapour fields}

Figure 4 shows the lidar observations of BSR, water vapour mixing ratio and wind velocity for the flight segment described in the previous section, with superimposed ECMWF analysis fields. The topography along the crosssection indicates the maximum elevations of the Cantabrian Mountains after the turn over the Atlantic at about $450 \mathrm{~km}$ distance, followed by the central Castilian plateau and the decline towards the Ebro valley. The BSR depicts clouds at $\sim 3 \mathrm{~km}$ altitude in the first part of the flight segment and low aerosol content $(\mathrm{BSR}<3)$ in the troposphere above the clouds (Figure 4(a)). The symmetric appearance in the cloud structure before and after the turn is due to the spatial proximity of the probed air masses in the southwesterly flow. The cloud-top height increases slightly towards the north and is associated with a capping temperature inversion (identified by dropsonde observations, not shown). The cloud-top height is significantly lower $(\sim 1 \mathrm{~km})$ in the marine PBL over the sea. Further to the east (at about $700 \mathrm{~km}$ distance in Figure 4(a)), the absence of a capping inversion and a warmer PBL presumably prevented cloud formation (Figure 3). However, also in this region, a strong vertical aerosol gradient was observed. The upper edge of the layer $(B S R \approx 5)$ decreases rapidly from $\sim 3.5$ to $\sim 1.5 \mathrm{~km}$ towards the end of the flight segment. The aerosol in this layer is probably affected by PBL transport processes during the previous day. An elevated aerosol layer occurs above the PBL between 1256 and 1310 UTC at about $3 \mathrm{~km}$ altitude. Closer to the ground an aerosol layer with BSR values up to 20 and a depth of $1 \mathrm{~km}$ follows the terrain. A vertically constant humidity and a dry adiabatic lapse rate in dropsonde profiles at 1254 and 1304 UTC (not shown) reveal that this layer coincides with the mixed layer. The upper boundary of the residual and the mixed layers coincide at the end of the flight.

The ECMWF analyses are qualitatively in good agreement with the observed humidity and wind structure (Figure 4(b) 

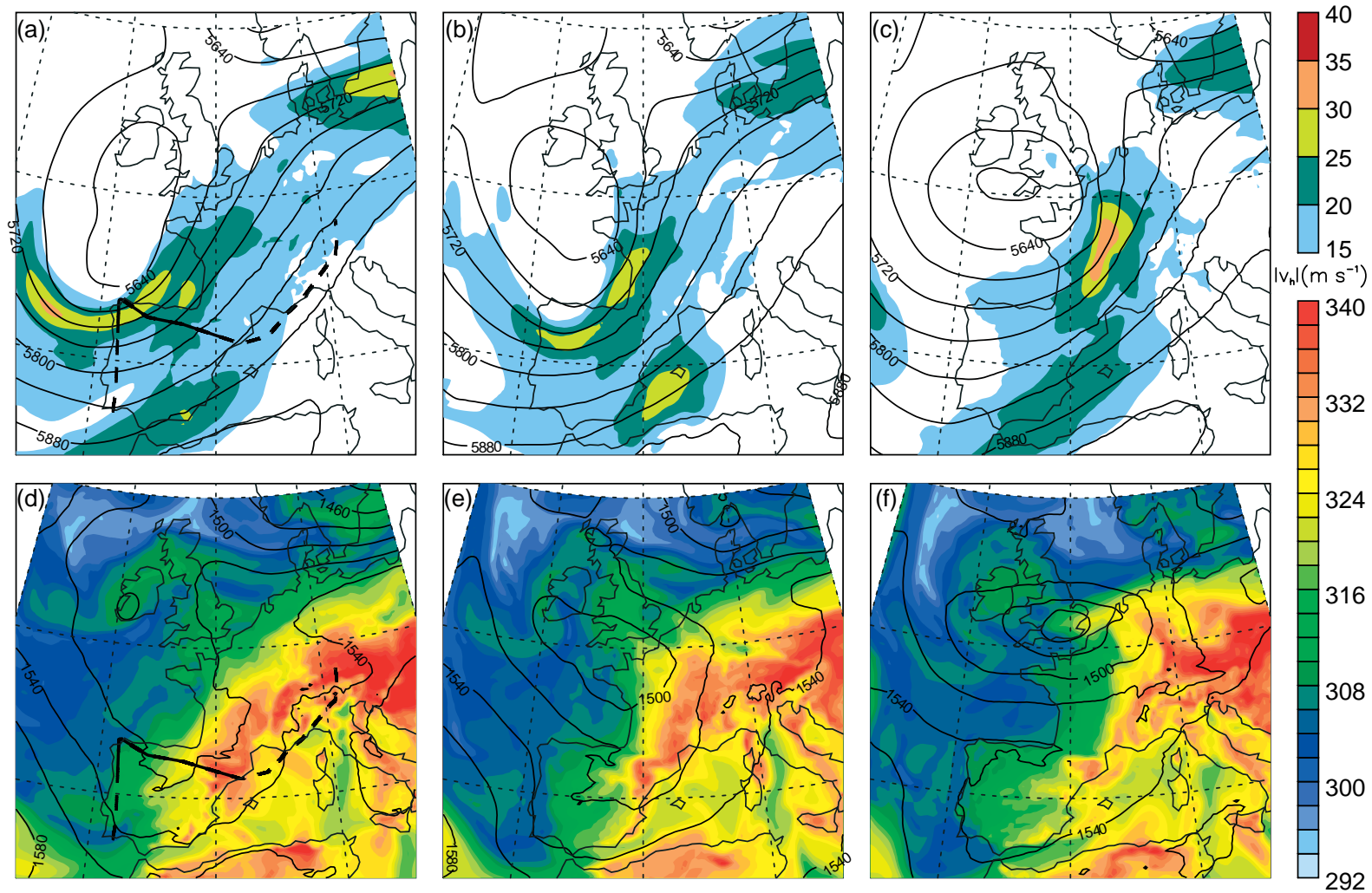

$\theta_{\mathrm{E}}(\mathrm{K})$

Figure 2. ECMWF analysis valid on 1200 UTC 19 July (a, d), 0000 UTC 20 July (b, e) and 1200 UTC 20 July 2007 (c, f). Geopotential height (m, black lines) and horizontal wind speed $\left(\mathrm{m} \mathrm{s}^{-1}\right.$, colour shaded areas) at $500 \mathrm{hPa}$ (a, b and c). Geopotential height ( $\mathrm{m}$, black lines) and equivalent potential temperature (K, colour shaded) at $850 \mathrm{hPa}$ (d, e and f). Thick black lines in (a) and (d) show the flight pattern of the DLR Falcon. The solid part indicates the section of collocated lidar measurements.


Figure 3. Terra MODIS visible satellite imagery: (a) composite of overpasses at 1150 (left part) and 1015 UTC (right part) on 19 July 2007 and (b) at 1225 (left part) and 1050 UTC (right part) on 20 July 2007. Available at: http://rapidfire.sci.gsfc.nasa.gov/

and (c)). Therefore, we use these data to facilitate the interpretation within data gaps that are due to cloudy regions and curve flights. A band of enhanced vertical moisture gradient approximately follows the cloud-top height and the upper boundary of the residual aerosol layer. This band separates moister air in the PBL from drier air above. The humidity in the northwestern part of the flight decreases vertically from values around $3 \mathrm{~g} \mathrm{~kg}^{-1}$ to values lower than $0.5 \mathrm{~g} \mathrm{~kg}^{-1}$ at this gradient. Over the Castilian plateau $(\sim 500 \mathrm{~km})$ the gradient band splits into two layers. The lower part extends eastwards and the humidity increases towards the end of the flight to maximum values of $\sim 11 \mathrm{~g} \mathrm{~kg}^{-1}$ inside the PBL. The well-mixed aerosol layer and the vertically nearly constant humidity values point to convective turbulence in this region. Moisture decreases from $\sim 9 \mathrm{~g} \mathrm{~kg}^{-1}$ in the mixed layer to values of $\sim 3 \mathrm{~g} \mathrm{~kg}^{-1}$ above. In the free atmosphere, the humidity is higher in the eastern part of the flight segment. The lowest humidity values $\left(<0.1 \mathrm{~g} \mathrm{~kg}^{-1}\right)$ occurred when the aircraft approached the jet region close to the trough centre (at around $250 \mathrm{~km}$ 

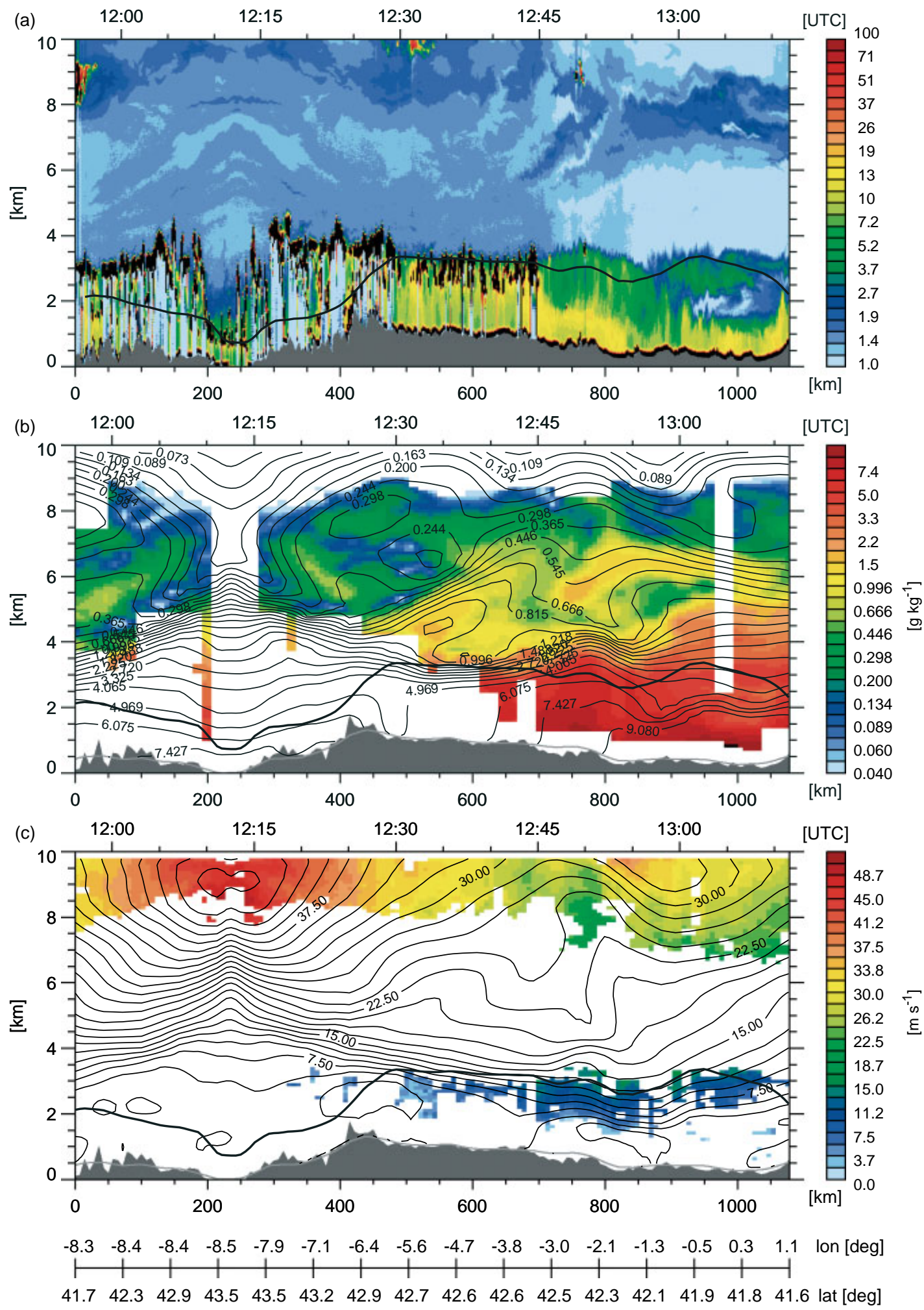

Figure 4. Lidar measurements on 19 July 2007: (a) atmospheric backscatter ratio at $1064 \mathrm{~nm}$ in logarithmic scale; (b) specific humidity $q$ (g kg ${ }^{-1}$ ) in logarithmic scale, superimposed with contour lines of ECMWF short-term forecast and analysis data; and (c) horizontal wind speed ( $\mathrm{m} \mathrm{s}^{-1}$ ), superimposed with ECMWF isotachs. Black line indicates the boundary layer height as diagnosed by the ECMWF IFS. Dark-grey areas show the topography interpolated from GLOBE-DEM (GLOBE Task Team et al., 1999); the light-grey line marks the topography interpolated from the ECMWF model.

distance). The moister upper-level air on the anticyclonic side (distance $>500 \mathrm{~km}$ ) of the jet is related to southerly advection.

The wind velocities (Figure 4(c)) reveal maximum values up to $45 \mathrm{~m} \mathrm{~s}^{-1}$ in the jet stream at $\sim 9 \mathrm{~km}$ altitude. The wind rapidly decreases towards lower levels and to the east, with a secondary upper level maximum near $2^{\circ} \mathrm{W}$. In the PBL winds are weak and range between 3 and $10 \mathrm{~m} \mathrm{~s}^{-1}$.

Additionally, Figure 4 shows the boundary layer height (BLH) from the operational analysis of the ECMWF's IFS interpolated on the flight track. This diagnosed BLH is located below the observed cloud-top height before 


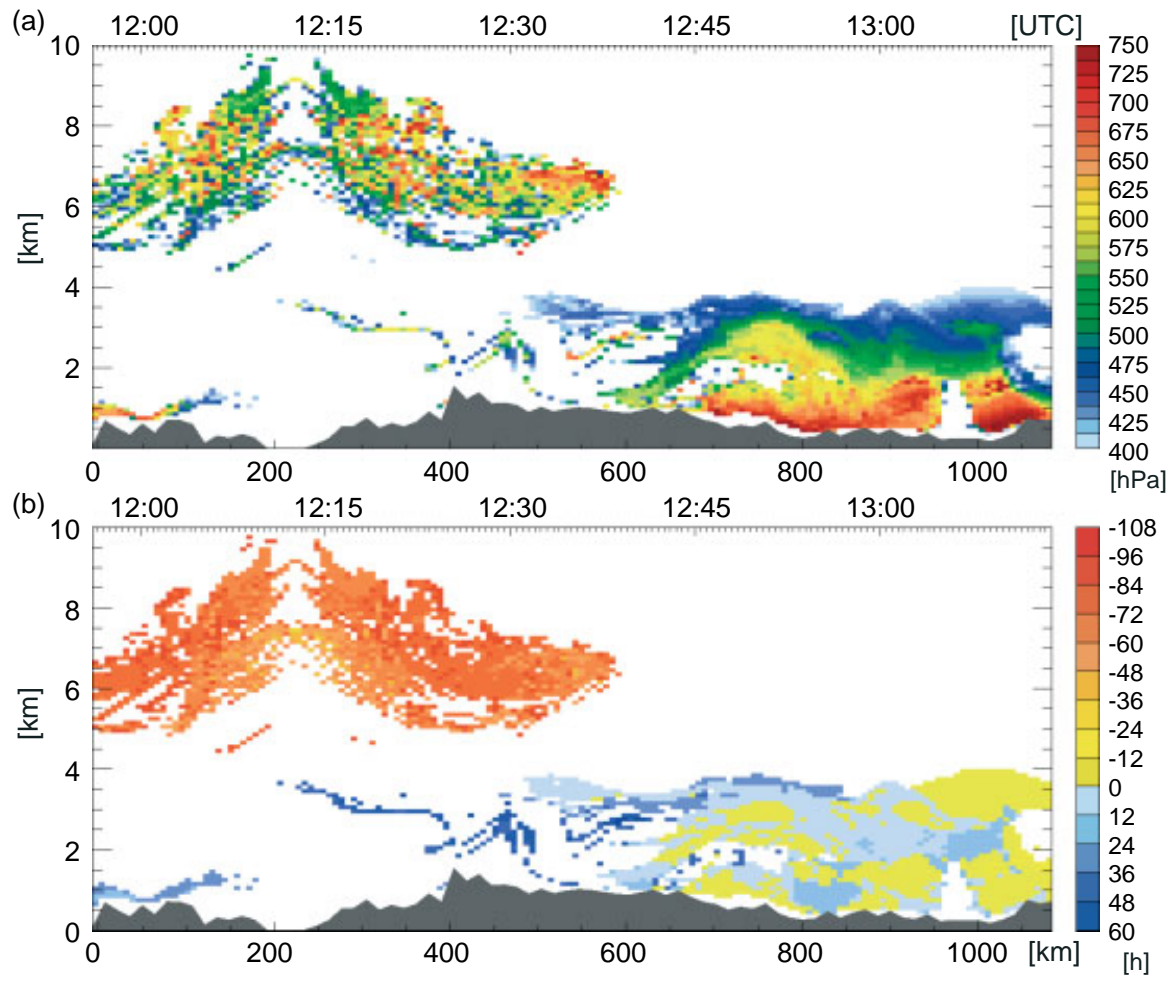

Figure 5. Locations of lidar observations with an ascent larger than $400 \mathrm{hPa}$ in $48 \mathrm{~h}$. (a) Magnitude of the maximum decrease of pressure $\Delta p_{\text {max }}$ (hPa) in $48 \mathrm{~h}$; (b) start time of the ascent (in hours relative to the observation time). For the method to calculate the trajectories see section 3.1.

1230 UTC (see Figure 4(a)). This might imply inaccurate convective activity over the mountainous terrain by the IFS. Remarkably, the agreement between the cloud top height and the BLH is nearly perfect over the flat area of the central Castilian plateau. Further east, the diagnosed BLH coincides with the upper edge of a residual layer visible by enhanced $\mathrm{BSR}$ values in the cloud-free region.

\subsection{WCB observation}

The method of calculating trajectories from every observation point (see section 3.1) was applied to this case study to identify measurements of WCB air parcels. Figure 5(a) shows the maximum ascent $\Delta p_{\max }$ identified as the magnitude of maximum pressure decrease within $48 \mathrm{~h}$ along the 7-day trajectory. Figure 5(b) depicts the time when the ascent begins relative to the time of the airborne lidar observation. Figure 5 illustrates the vertical structure of the WCB and, therefore, a threshold of the pressure decrease of at least $400 \mathrm{hPa}$ in $48 \mathrm{~h}$ is chosen. Two main regions can be distinguished. One region in the first part of the flight segment is located in the upper tropospheric jet region, which is characterized by very low humidity values (see Figure 4(b)). These air parcels are related to an ascent that took place $\sim 3$ days in advance of the observation (Figure $5(\mathrm{~b})$ ). The second region with large maximum ascent values appears in the humid PBL during the second half of the flight segment. This air mass in the lower troposphere flows into a WCB. The respective parcels just started to ascend or were about to start within $12 \mathrm{~h}$ after the observation (Figure 5(b)). The distribution of the maximum ascent values differs in the two regions (Figure 5(a)). The lower region shows coherent horizontally extended layers of equal magnitude in $\Delta p_{\max }$ and, generally, a vertical decrease in $\Delta p_{\max }$. Conversely, the $\Delta p_{\max }$ distribution at upper levels is noisy and features a large variability without any remarkable layering or coherence.

Pathways of WCB trajectories that satisfy the 'standard WCB criterion' of ascent larger than $600 \mathrm{hPa}$ are shown in Figure 6(a) and (b). The two different WCB regions identified in the cross-sections can be clearly distinguished by colour (see also the pressure of the trajectories at 19 July 1200 UTC in Figure 6(c)). The green and blue trajectories cross the western part of the lidar curtain in the upper troposphere above $500 \mathrm{hPa}$. As shown in Figure 6(c), these parcels had already ascended 2-3 days before the flight. After the ascent over Western Europe, the parcels are embedded in the trough circulation and travel from Scandinavia to the Iberian Peninsula in $\sim 36 \mathrm{~h}$. The air parcels again move to the north after the observation. In agreement with the small positive values for the second region in Figure 5(b), the reddish parcels ascend directly after having passed the eastern part of the cross-section in a temporally and spatially coherent belt over France (see pressure evolution in Figure 6(c)). In the late outflow phase the coherent belt splits into three branches. During their ascent, parcels lose most of their water vapour (Figure 6(d)), which initially varies between 5 and $10 \mathrm{~g} \mathrm{~kg}^{-1}$. Additionally, the potential temperature increases due to latent heating (Figure 6(e)). The backward part of the trajectory calculation shows that most parcels are transported on the rear side of the persistent trough and either descend slightly or move close to sea level. Whereas most air parcels move over the Iberian Peninsula prior to the lidar observation time, another branch with parcels approaches from the Mediterranean to the south of Sicily and Sardinia. Interestingly, the ascent of parcels in both branches takes place at approximately the same position over France (Figure 6(a) and (b)).

Figure 7 depicts the starting position (a), the maximum pressure decrease $\Delta p_{\max }$ (b) as well as the pressure (c) and 

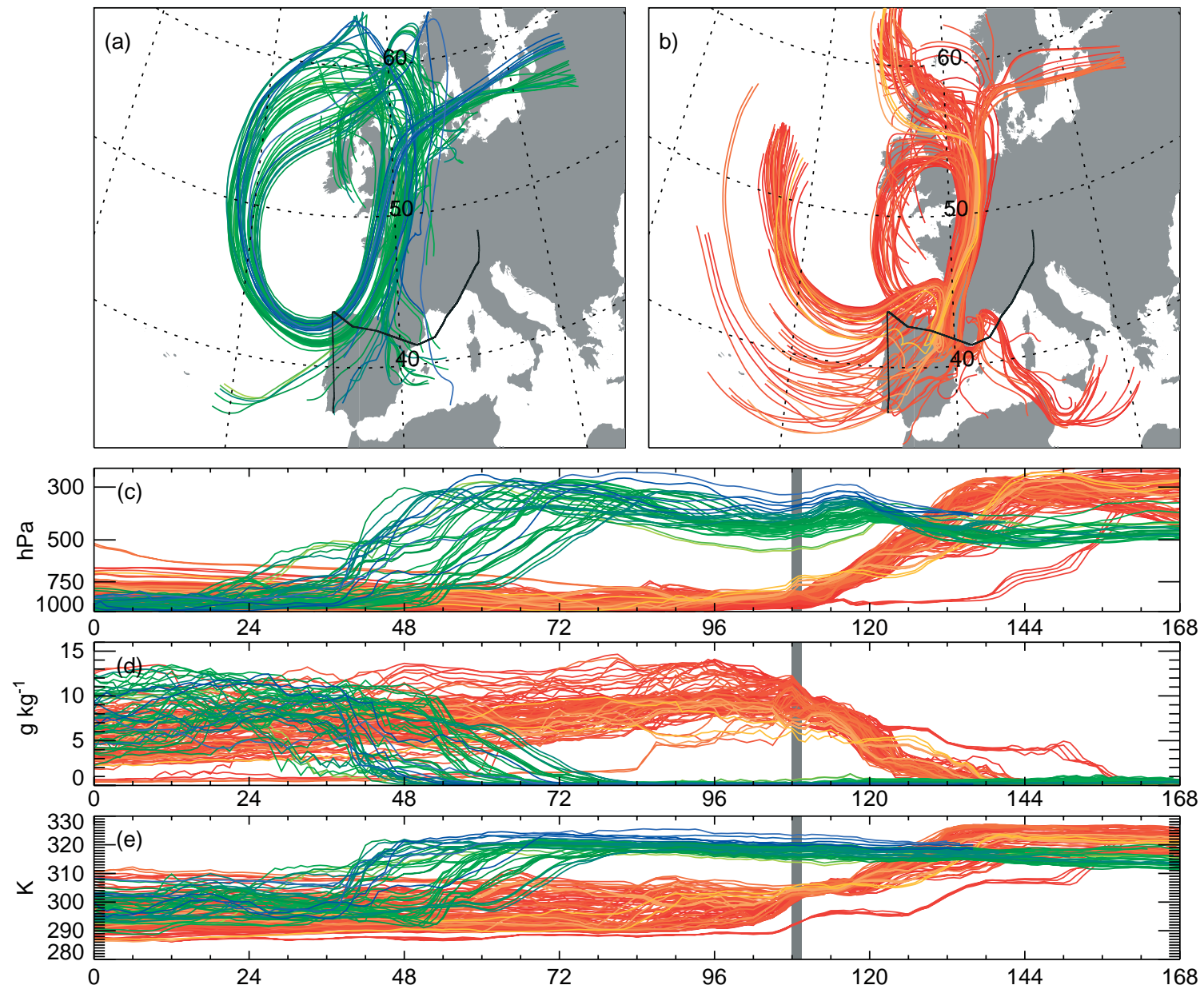

Figure 6. WCB trajectories ascending more than $600 \mathrm{hPa}$ in $48 \mathrm{~h}$. Trajectories are colour-coded in dependence of the pressure at the time of the observation. (a) The WCB ascent in advance and (b) after the observation. Black line in (a) and (b) indicates the flight track. The thick part corresponds to the section of collocated lidar observations. Temporal development of pressure (c), specific humidity (d) and potential temperature (e). Time (hours) is relative to 0000 UTC 15 July. For a clear overview every second trajectory (coloured according to the pressure at the time of observation) is shown. For the method to calculate the trajectories see section 3.1. The grey bar in (c), (d) and (e) indicates the time of the lidar observations.

humidity (d) evolution for the WCB trajectories which ascend after the flight intersection (reddish parcels in Figure 6). The eastern portion of the WCB consists of air parcels (orange and red) that originate from the Mediterranean. They form the branch of parcels with the anticyclonic outflow towards Russia. Trajectories with maximum ascent (up to $774 \mathrm{hPa}$ ) are located at the centre of the WCB (Figure 7(b)). These air parcels are predominantly advected from the Atlantic (to the west of $20^{\circ} \mathrm{W}$ and north of $50^{\circ} \mathrm{N}$ ). They differ from the rest of the Atlantic trajectories by moving at low levels (Figure 7(c)) southward over the Bay of Biscay towards the observation location. The Mediterranean trajectories exhibit a larger $48 \mathrm{~h}$ ascent than the southern portion of the Atlantic ones. They also move close to the sea surface, accompanied by a humidification due to surface fluxes (Figure $7(\mathrm{~d})$ ). During the rapid ascent the parcels quickly lose their moisture, which decreases to less than $0.5 \mathrm{~g} \mathrm{~kg}^{-1}$ when they reach the outflow region. The $48 \mathrm{~h}$ decrease of moisture within the WCB $\left(\Delta p_{\max }>600 \mathrm{hPa}\right)$ varies from 6 to $14.3 \mathrm{~g} \mathrm{~kg}^{-1}$. The mean humidity loss along all trajectories is $10.3 \mathrm{~g} \mathrm{~kg}^{-1}$. The corresponding $48 \mathrm{~h}$ change in potential temperature amounts to $27.6 \mathrm{~K}$ on average with minimum and maximum values of 17.7 and $34.7 \mathrm{~K}$, respectively.

Additionally, all panels in Figure 7 show the positions of the observed parcels at different times during the
WCB ascent by means of black dots. The parcels are located close together near the flight path over southwestern France between 700 and $550 \mathrm{hPa} 12 \mathrm{~h}$ after the observation (Figure 7(a)). Another $12 \mathrm{~h}$ later, at 1200 UTC 20 July (Figure 7(b)), the parcels begin to spread horizontally and vertically. The fastest parcels already reach the upper troposphere over the UK. The slower ones remain in the mid troposphere over northeastern France. Of course, only a part of the air that is lifted within the developing system is probed by the lidar measurements. However, comparing the positions in Figure 7(b) with the MODIS image (Figure 3) it can be confirmed that the observed air mass was embedded in the cloud system of the cyclone.

\subsection{Differences between ECMWF data and lidar observa- tions}

Figure 8 shows the difference between ECMWF data and lidar observations of specific humidity (Figure 8(a)) and the horizontal wind velocity (Figure $8(\mathrm{~b})$ ) along the lidar cross-section. In the eastern part of the flight segment a strong positive moisture deviation beneath $3 \mathrm{~km}$ indicates an overestimation of the humidity by the IFS. The deviations reach up to $7 \mathrm{~g} \mathrm{~kg}^{-1}$ (corresponding to a relative difference of $100 \%$; see section 3.2) and are located in the region of strong subsequent ascent. It is noteworthy that this significant 



Figure 7. Positions of WCB trajectories ascending more then $600 \mathrm{hPa}$ in $48 \mathrm{~h}$ after the observation (see Figure 6(b)). Colour coding in upper row depends on longitude of the starting position along the flight segment (a) and maximum pressure decrease $\Delta p_{\max }$ in $48 \mathrm{~h}$ (b). The bottom row is colour-coded dependent on pressure (c) and moisture content (d) at the parcel positions along the respective trajectory. Black dots indicate position for 0000 UTC 20 July (a, corresponding to the $120 \mathrm{~h}$ time mark in Figure 6), 1200 UTC 20 July (b), 0000 UTC 21 July (c) and 1200 UTC 21 July 2007 (d). For a clear overview every second trajectory is shown.

moisture bias occurs in the WCB inflow region, i.e. within an airflow that is of great importance for the subsequent dynamical evolution of the probed weather system. Based on Figure 5 we defined an approximate inflow region (blue rectangle in Figure 8) below $3 \mathrm{~km}$. Averaged over this inflow region the mean moisture bias is $\sim 1.0 \mathrm{~g} \mathrm{~kg}^{-1}(14 \%)$. Above, a region with negative deviations $\left(\sim 2 \mathrm{~g} \mathrm{~kg}^{-1}\right)$ exists. The absolute deviations are smaller at low moisture contents in the upper troposphere. However, the partly high relative deviations (up to $200 \%$, not shown) indicate a significant overestimation of humidity in the upper troposphere. It is difficult to address the deviations associated with the outflow region of the western $\mathrm{WCB}$ where the parcels ascended 3 days earlier. As discussed before, this region is less homogeneous compared to the inflow region (see Figure 5). Note that the deviation in the eastern part of the inflow region is smaller close to the ground, which could be an effect of a better representation of the developing mixed layer in the IFS.
The absolute wind deviations (Figure 8(b)) are largest at upper levels (between -3 and $+7 \mathrm{~m} \mathrm{~s}^{-1}$ ) at higher wind speeds. Averaged over the inflow region the wind speed is underestimated by the IFS by $-1.3 \mathrm{~m} \mathrm{~s}^{-1}(-18 \%)$. However, below $1.5 \mathrm{~km}$ wind speed is typically overestimated.

A comparison of profiles from the lidar measurements, IFS data and a dropsonde profile, in the area of overestimated humidity in the WCB inflow, is presented in Figure 9. Note that the line-like dropsonde measurement is compared to a lidar profile consisting of an accumulation of laser shots. The specific humidity measured by dropsonde and lidar are in good agreement and show the same shape of the vertical humidity distribution (see Figure 9(a)). Two lidar humidity profiles are shown since the dropsonde was launched temporally in between. To some extent differences can be explained by the different character of the measurement as well as by the horizontal drift of the dropsonde with the southwesterly wind perpendicular to the flight track. The dropsonde profile confirms the overestimated humidity 



Figure 8. Absolute differences of ECMWF short-term forecasts and analyses and lidar observations on 19 July 2007, of the specific humidity (a) and the horizontal wind velocity (b). Blue rectangle indicates the approximated WCB inflow region. Black line in (a) indicates boundary layer height as diagnosed by the ECMWF IFS. Dark-grey areas show topography interpolated from GLOBE-DEM (GLOBE Task Team et al., 1999).

of the IFS runs between 1.3 and $2.5 \mathrm{~km}$ altitude and the smaller deviation below. Above $3 \mathrm{~km}$ the model is able to represent the general decrease of moisture with height, but it does not resolve the fine structures, probably due to the limited resolution. The wind velocity of the lidar profile and the simultaneous dropsonde are in very good agreement. Also the wind velocity profile from the IFS compares very well with the observations. The WCB inflow region is characterized by overestimated wind velocities at low wind speeds beneath $2 \mathrm{~km}$ altitude.

\subsection{Moisture uptake analysis}

In the previous section a strong moisture difference between the IFS and the lidar observations has been discovered in the WCB inflow region. Figure 4 shows that the BLH as diagnosed by the ECMWF's IFS coincides with an observed elevated residual layer at $\sim 3 \mathrm{~km}$ altitude. Figure 9(a) indicates nearly constant humidity values in the residual layer between 1.6 and $3 \mathrm{~km}$ observed by lidar and dropsonde $\left(\sim 4 \mathrm{~g} \mathrm{~kg}^{-1}\right)$. The ECMWF model does not capture the structure of the lower evolving boundary layer, as shown by the differing vertical humidity profiles below $2 \mathrm{~km}$. As the layer of increased humidity deviations is located inside
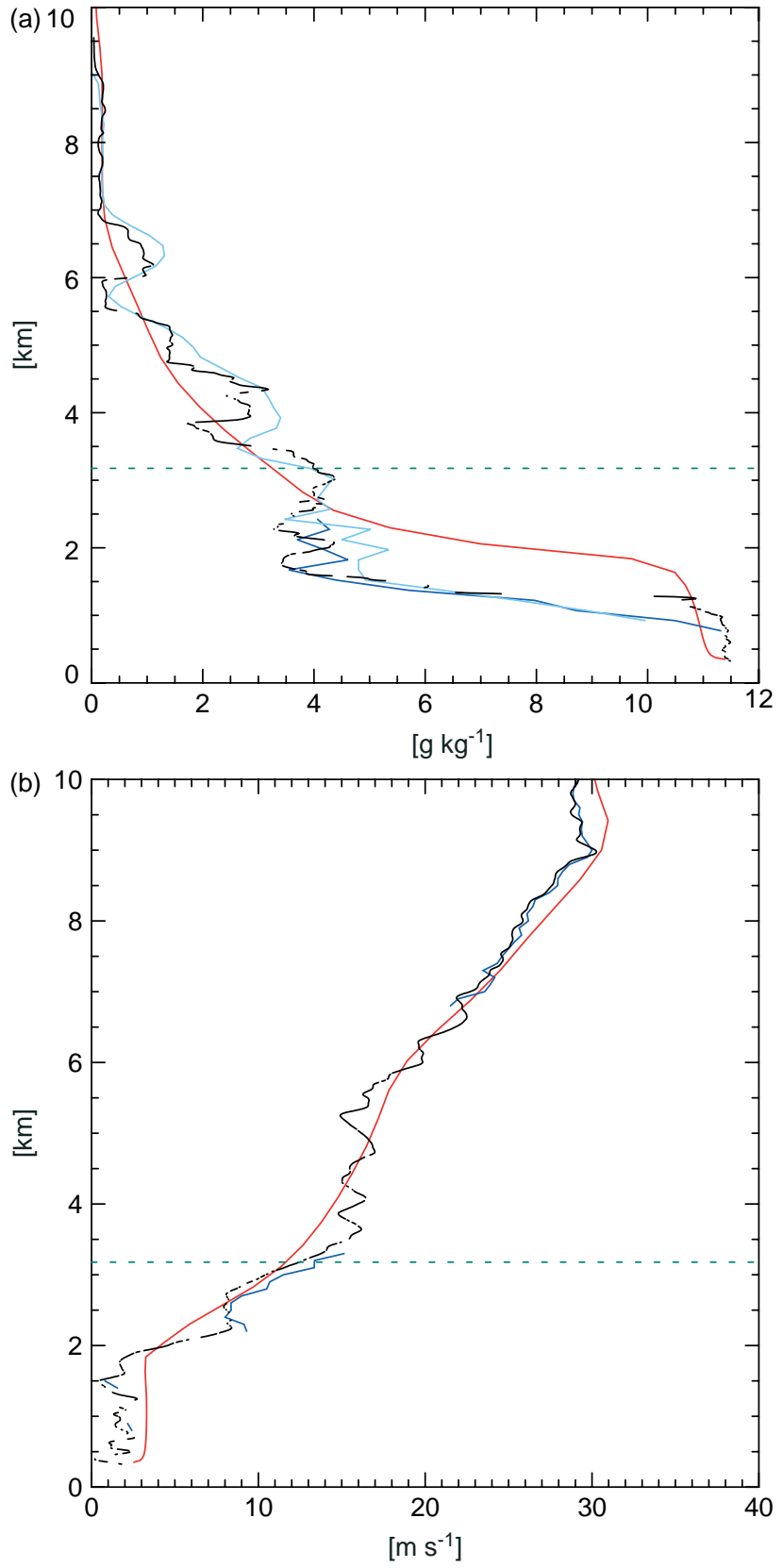

Figure 9. Dropsonde comparison on 19 July 2007. (a) Mixing ratio from dropsonde (black line, at 1304 UTC), ECMWF (red line, interpolated to the same time and position) and DIAL (light-blue profile at 1304 UTC, dark-blue at 1305 UTC). (b) Same for wind velocity but with wind lidar profile at 1304 UTC (dark-blue line). Dashed green line indicates boundary layer height as diagnosed by the ECMWF IFS.

the ECMWF boundary layer (see Figure 8(a) and 9(a)) one might guess that a too strong parameterized turbulent mixing distributed the humidity in the model over a too deep layer. The somewhat deeper $(\sim 1.9 \mathrm{~km})$ and less moist $\left(\sim 11 \mathrm{~g} \mathrm{~kg}^{-1}\right)$ evolving mixed layer in the IFS compared to the mixed layer observed by the dropsonde $(\sim 1.3 \mathrm{~km}$ and $11.5 \mathrm{~g} \mathrm{~kg}^{-1}$ ) in Figure 9(a) supports this hypothesis. However, the probably incorrectly represented local mixing in the IFS cannot explain the integrated moisture excess that occurs up to $\sim 3 \mathrm{~km}$ altitude. Therefore it is interesting to further investigate the potential processes that led to the overestimated humidity in the ECMWF model. Figure 7 gave a first indication that the air mass observed in the eastern part of the flight segment originated from the 
Mediterranean (see also section 4.3). These trajectories show an increase in specific humidity while they were advected close to the surface. The history of the probed air masses and the related moisture uptake will be discussed based on 7.5-day backward trajectories that have been calculated from the WCB inflow region (see Figure 8) for every lidar observation point. For these trajectories the moisture source diagnostic introduced by Sodemann et al. (2008) and Pfahl and Wernli (2008) was applied to analyse the location and time of the moisture uptake. In essence, the technique uses material changes of specific humidity along trajectories to quantitatively diagnose moisture uptakes due to surface evaporation. Oceanic uptakes (mixing of advected air with moisture evaporated from sea surface) and continental uptakes (evaporation from the soil and transpiration from plants) can be distinguished. These processes crucially depend on sub-grid scale processes which are parameterized by turbulent humidity fluxes. The subsequent analysis aims at clarifying whether enhanced deviations can be attributed to an increased moisture uptake and/or to distinct uptake regions.

The trajectories in the WCB inflow region can be divided into five clusters with characteristic transport behaviours. Figure 10(a) shows the positions of the backward trajectories at 1200 UTC 17 July (i.e. $49 \mathrm{~h}$ prior to the observation). The clustering was defined by the area encompassing characteristic groups of parcel positions. The yellow, light-blue and dark-blue trajectory clusters (Figure 10(b)) originate from the Atlantic. The dark-blue air parcels are travelling comparatively fast on the backside of the trough while descending from higher altitudes $(\sim 500 \mathrm{hPa})$. The light-blue coloured trajectories also illustrate a transport over the Iberian Peninsula. However, their locations are much closer to the ground and they experienced longer residence times over land. The yellow trajectories perform loops over the Bay of Biscay. The Mediterranean trajectories are divided into two clusters. In contrast to the green trajectories that move along the northern coast of Spain, the red parcels are transported further to the south and are characterized by long residence times (3.5 days) off the coast of Spain $\left(\right.$ at $\left.\sim 0^{\circ} \mathrm{E} / 39.5^{\circ} \mathrm{N}\right)$. Figure 10 (c) illustrates the location of the five clusters on the lidar cross-section. The trajectories that travel over the Iberian Peninsula (light and dark blue) belong to starting points in the upper part of the inflow area. The highest starting points at driest humidity values in the inflow region are associated with the descending dark-blue trajectories. Beneath, the remaining trajectories from the Atlantic (yellow) start in the western part of the lidar subsection. The Mediterranean trajectories (red and green) are associated with the air mass that was probed at the end of the flight below about $2 \mathrm{~km}$.

The identified moisture uptake regions for all trajectories from the WCB inflow region are shown in Figure 11. Altogether, $77 \%$ of the ECMWF moisture at the trajectory starting points can be related to uptake in these regions. Different regions with oceanic and continental moisture uptakes appear that can be associated with the five different clusters. The moistening of the yellow trajectories is reflected in the uptake region over the Bay of Biscay and indicates that high moisture values in the western part of the WCB inflow region arise from evaporation over the Atlantic. The light- and dark-blue trajectories can be associated with weak moisture uptake over the Iberian Peninsula. The green and red trajectories experience strong moisture uptake over the Mediterranean and the northeastern part of Spain. In particular for the green cluster, a distinct maximum occurred between Corsica and France.

Figure 12 links the accumulated moisture uptake along the trajectories with the moisture deviations between the IFS and the lidar observations. The highest uptake values (8-12 $\mathrm{g} \mathrm{kg}^{-1}$ during the 7.5 days) occurred in the eastern

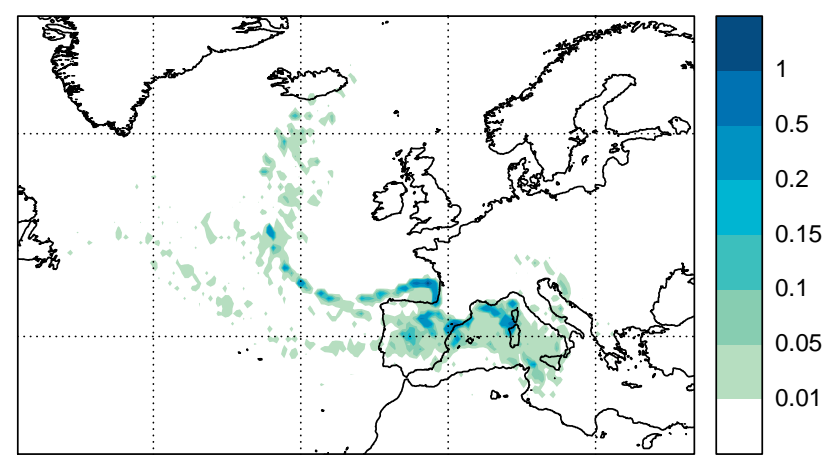

Figure 11. Moisture uptake regions for trajectories starting in WCB inflow region (see Figure 10). Units are $\%$ of final humidity $1000 \mathrm{~km}^{-2}$.
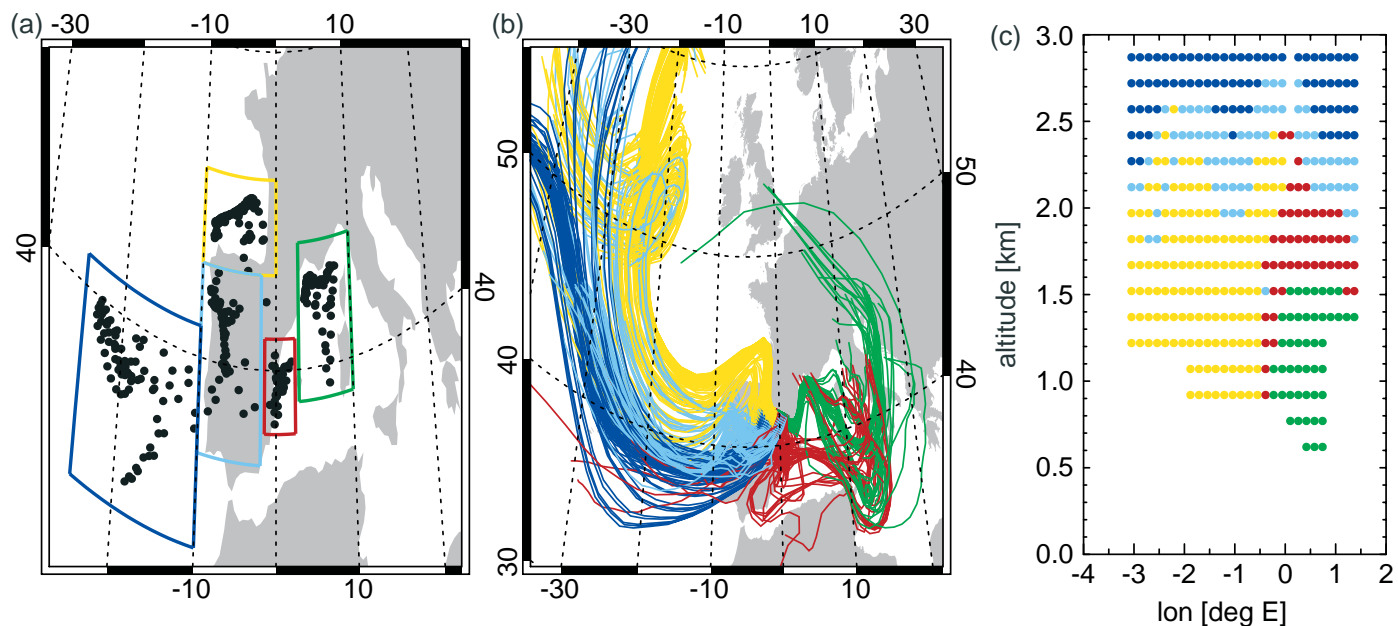

Figure 10. Clustering of backward trajectories starting in WCB inflow region along the lidar curtain (see Figure 8(a)) based on different transport characteristics. (a) Trajectory positions at 1200 UTC 17 July 2007 ( -49 h) defining the five different clusters; coloured rectangles indicate clustering regions; (b) positions of the trajectories; (c) starting positions along the lidar cross-sections; (b) and (c) are coloured in accordance with the five clusters. 
part of the flight segment (Figure 12(a)). The maximum positive moisture deviations (Figure 12(b)) occur in the upper part of this area, with high total moisture uptake values. This indicates that a high total moisture uptake does not necessarily lead to a high deviation. However, interestingly, both high moisture uptake and large deviations are associated with the Mediterranean trajectories (see red and green dots in Figure 10(c)). For this reason the Mediterranean clusters (green and red) are investigated in more detail, especially during the first $25 \mathrm{~h}$ along the backward trajectories (from
1300 UTC 19 July to 1200 UTC 18 July) when the air parcels are close together.

Figure 13 shows the positions and characteristics of trajectories with a high total moisture uptake within this period (exceeding $1.5 \mathrm{~g} \mathrm{~kg}^{-1}$ in $25 \mathrm{~h}$ ). The air parcels that fulfil this criterion are shown in Figure 13(a) (black squares) together with the associated moisture deviation. This subgroup of the Mediterranean trajectories covers well the main region with high positive deviations. The moisture uptakes along these trajectories mainly took place over land
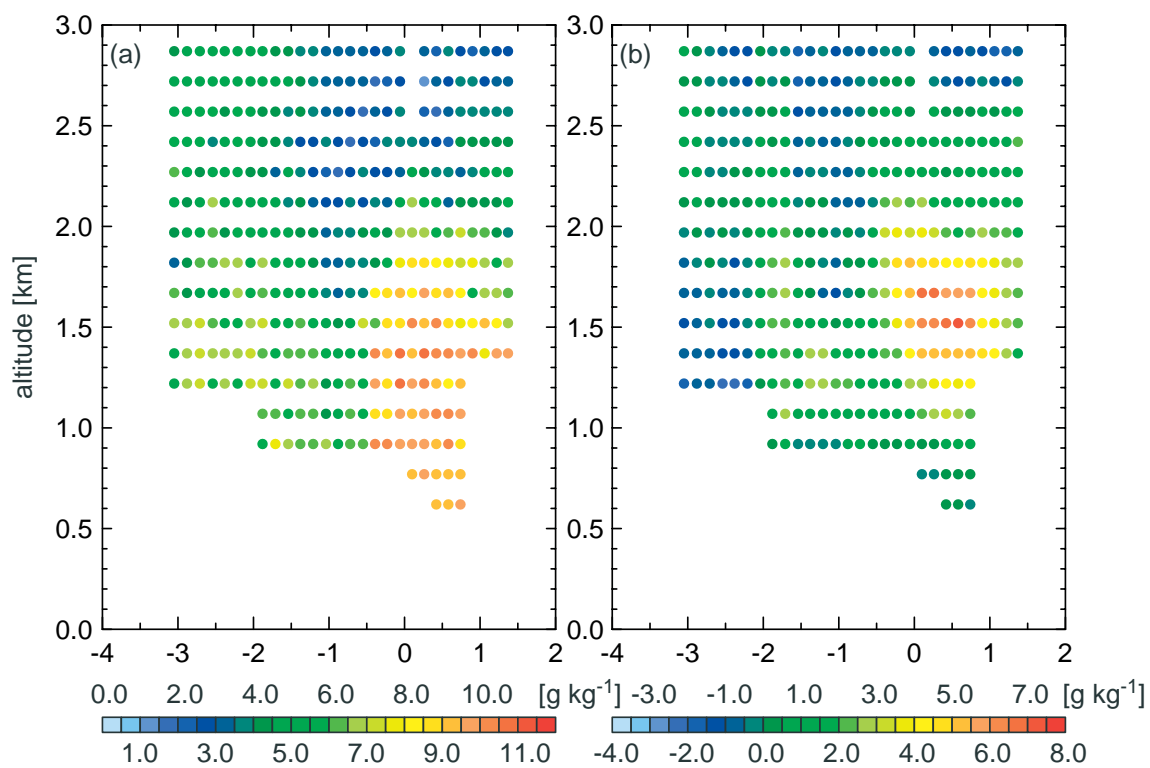

Figure 12. Starting points of backward trajectories in the WCB inflow region (see also Figure 8(a)). (a) Total (7.5-day) moisture uptake along the respective trajectory; (b) moisture deviation (IFS - LIDAR; note that the colour bar is different from Figure 8(a)).


Figure 13. Starting points and trajectories that originate from the Mediterranean Sea and possess a total moisture uptake larger than $1.5 \mathrm{~g} \mathrm{~kg}^{-1}$ in $25 \mathrm{~h}$. (a) Moisture deviation $\left(\mathrm{g} \mathrm{kg}^{-1}\right.$ ) with black markers showing starting positions of the trajectories; (b) location and strength of moisture uptakes; black line indicates inflow area on the flight track; (c) temporal evolution of pressure along the trajectory together with moisture uptakes (dots); and (d) temporal evolution of the moisture uptake along the trajectory. Red and green colouring of the trajectories is analogous to the clusters defined in Figure 10. 
above the eastern part of the widening Ebro valley floor as well as on its flanks (Figure 13(b); see also total moisture uptake field in Figure 11). The red trajectories primarily move over the mountains located in the south and descend to the valley floor (Figure 13 (c)) between $-25 \mathrm{~h}$ and $-12 \mathrm{~h}$. The green parcels move close to the sea surface. The ascent of all trajectories towards the flight track in the last $12 \mathrm{~h}$ indicates the initial phase of the WCB ascent. Figure 13(d) shows the magnitude of the moisture uptake. The red trajectories possess the largest uptakes during the late phase of their descent $(-19 \mathrm{~h}$ and $-13 \mathrm{~h})$. The green trajectories mainly moisten when they reach land at $-1 \mathrm{~h}$ and $-7 \mathrm{~h}$. During these $25 \mathrm{~h}$, accumulated moisture uptakes over land are substantial and amount to roughly $3 \mathrm{~g} \mathrm{~kg}^{-1}$.

We conclude that the main moisture uptakes that can be associated with the strong moisture deviation of the IFS with respect to the lidar data occurred over land in the Ebro valley. This leads to the hypothesis that landsurface evapotranspiration may be crucial for accurately capturing the moisture content in the inflow of WCBs, at least during summer when evapotranspiration can be particularly intense and in regions where the airflow into WCBs originate (partially) from continental areas.

\section{Discussion and conclusions}

In this study we analysed a large set of airborne lidar missions with water vapour (and wind) observations over the northern Atlantic and Europe with respect to the occurrence of warm conveyor belts. By checking for suitable geographical and meteorological situations, 17 of the 83 missions were investigated for intersections with WCB trajectories. The ETReC 2007 mission on 19 July 2007 over Spain was selected as it showed observations in the outflow of a first and inflow of a second WCB. This enabled, for the first time, a detailed investigation of the humidity structure in the inflow region of a WCB as revealed by lidar remote sensing profiles. Previous studies showed that this WCB was associated with a cyclone which caused highimpact weather, especially high amounts of rain over the UK (Blackburn et al., 2008).

Cyclogenesis on the leading edge of a large-scale trough led to the development of a low-level frontal system over France. A Lagrangian diagnostic with forward and backward trajectory calculations from every observation point was performed to directly associate observations with WCB air masses. Two independent WCB events were observed. One WCB was probed by the lidar that ascended into the upper troposphere 2-3 days prior to the measurements. The second event corresponded to a WCB air mass that underwent a strong ascent immediately after being observed by the lidar. This WCB air mass at low levels was located in the warm sector of the developing cyclone. The WCB ascended coherently ahead of the cold front after being probed by the lidar and spread out when reaching the outflow region over southern Scandinavia.

On average, the trajectories exceeding an ascent of $600 \mathrm{hPa}$ lost $10.3 \mathrm{~g} \mathrm{~kg}^{-1}$ of their initial humidity and increased their potential temperature by $27.6 \mathrm{~K}$ in $48 \mathrm{~h}$. During the 4.5 days before the observation most of these parcels were advected within a stationary trough from the Atlantic Ocean and either descended to or moved close to sea level. Another branch originated above the Mediterranean at low levels, showing a strong moistening due to surface evaporation. The advection of moistened air parcels influenced the humidity distribution portrayed by the lidar measurements. A comparison revealed that on average the humidity in the inflow region was overestimated by the ECMWF analysis by $1.0 \mathrm{~g} \mathrm{~kg}^{-1}(14 \%)$ compared to the lidar. Although this average deviation is within the general uncertainty of humidity values in operational analyses, local peak deviations of up to $7.0 \mathrm{~g} \mathrm{~kg}^{-1}$ were identified. These very large deviations occur in the inflow region of a WCB and are thus of particularly high dynamical relevance.

The analysis of the diagnosed BLH in the IFS model and the comparisons of lidar and dropsonde observations with the modelled humidity indicated that incorrect local mixing associated with an overestimated height of the mixed layer only partly explains the observed moisture deviation. A detailed investigation of 7.5-day backward trajectories starting in the WCB inflow region showed that most parcels associated with a large positive moisture bias were transported over the Mediterranean. A moisture source diagnostic illustrated that high total moisture uptakes occurred in these air parcels over the Mediterranean Sea and also over the eastern part of the Iberian Peninsula. The analysis of the moisture uptakes within $24 \mathrm{~h}$ prior to the observation indicates a strong influence of evapotranspiration in the Ebro valley. This analysis gives some support that the excess moisture in the inflow region is related to insufficiently represented evapotranspiration processes in the IFS. However, incorrect moisture transport, either horizontal or vertical, the latter due to inaccurate representation of the turbulent boundary layer, has also contributed to the diagnosed moisture deviation.

As described in the Introduction, the moisture supply critically influences diabatic processes in the WCB. Therefore the diagnosed wet bias at low levels may affect the forecast of this WCB and the downstream flow evolution. The situation of this summer season WCB over the continent is further complicated by strong convective cells embedded in the $\mathrm{WCB}$, as revealed by satellite observations. To investigate the impact of the moisture bias in the ECMWF analysis on the prediction of the flow evolution, we intend to perform sensitivity experiments applying a mesoscale model with varying initial moisture distributions.

\section{Appendix}

\section{A1. Influence of the temporal resolution on the WCB detection method}

For the calculation of Lagrangian trajectories a multitude of temporal and spatial interpolations are required. During recent years the spatial resolution of NWP models like the IFS has been significantly increased which, finally, improved the accuracy of trajectory calculations. However, it can be supposed that a higher temporal resolution would further increase the accuracy. In this study we used a 3-hourly time resolution in the driving wind fields for calculating the trajectories. The 6-hourly analyses were supplemented by short-term forecasts. For the comparison of the continuous lidar measurements we calculated a special 1-hourly data output with the ECMWF IFS. In the following, the influence of the time resolution on the detection of the WCB will be quantified. To this end, the trajectory calculations were repeated with a 1- and 6-hourly time resolution of the input wind fields. 


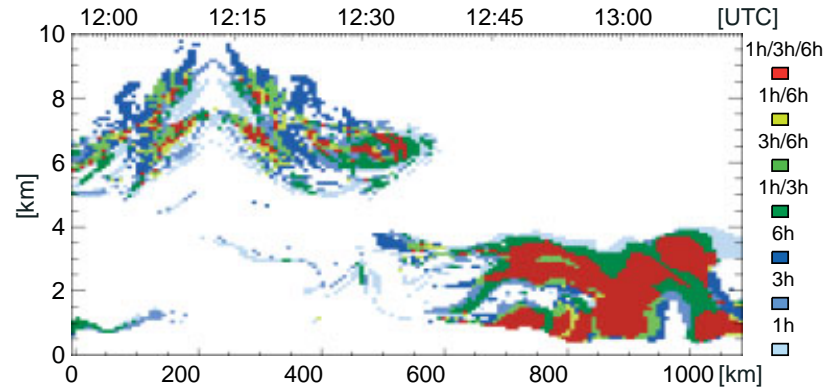

Figure A1. Location of WCB observations (pressure decrease larger than $400 \mathrm{hPa}$ ). Colour coding indicates temporal resolution of the trajectory calculation in which the trajectory is identified as WCB air parcel.

Figure A1 demonstrates the sensitivity of the detection algorithm to the temporal resolution of the driving wind fields. The classifications illustrate observations with ascents larger than $400 \mathrm{hPa}$ (same as used in Figure 5) detected by either one, two or by all temporal resolutions. The noisy character of the upper tropospheric $\mathrm{WCB}$ region is also manifested in this diagnostic. This implies that the detection of this WCB is particularly sensitive to the temporal resolution of the driving meteorological analyses. At lower altitudes large areas are found where at least two resolutions detected WCBs (see Figure 5(a)). The algorithm consistently identifies the air that is lifted right after the observation time independent of the temporal resolution. It would be of great interest to investigate this sensitivity aspect in a more general way for different cases and regions.

\section{Acknowledgements}

The authors are grateful for the efforts of the pilots and system operators, which enabled the successful planning and realization of the mission flights. Especially, we thank Stephan Rahm and Martin Wirth (both DLR) for processing the lidar data. We appreciate the help of Reinhold Busen for processing the dropsonde data. The authors thank the European Centre for Medium-Range Weather Forecasts (ECMWF) for providing data in the framework of the special project 'Support Tool for HALO missions'. The work of AS was funded by the German Research Foundation (DFG) within the Priority Program SPP 1167 QPF (Quantitative Precipitation Forecast). The internal review by Kersten Schmidt helped to improve the manuscript. We are also grateful for the constructive remarks by John Methven and another anonymous reviewer.

\section{References}

Bethan S, Vaughan G, Gerbig C, Volz-Thomas A, Richer H, Tiddeman DA. 1998. Chemical air mass differences near fronts. J. Geophys. Res. 103: 13413-13434.

Bhawar R, Di Girolamo P, Summa D, Flamant C, Althausen D, Behrendt A, Kiemle C, Bosser P, Cacciani M, Champollion C, Di Iorio T, Engelmann R, Herold C, Pal S, Wirth M Wulfmeyer V. 2011. The water vapour intercomparison effort in the framework of the Convective and Orographically-induced Precipitation Study: airborne-to-ground-based and airborne-to-airborne lidar systems. $Q$. J. R. Meteorol. Soc. 137(S1): 325-348.

Blackburn M, Methven J, Roberts N. 2008. Large-scale context for the UK floods in summer 2007. Weather 63: 280-288.

Browell EV, Danielsen EF, Ismail S, Gregory GL, Beck SM. 1987. Tropopause fold structure determined from airborne lidar and in situ measurements. J. Geophys. Res. 92: 2112-2120.
Browning KA, Hardman ME, Harrold TW, Pardoe CW. 1973. Structure of rainbands within a mid-latitude depression. Q. J. R. Meteorol. Soc. 99: $215-231$.

Carlson TN. 1980. Airflow through midlatitude cyclones and the comma cloud pattern. Mon. Weather Rev. 108: 1498-1509.

Cooper OR, Moody JL, Parrish DD, Trainer M, Ryerson TB, Holloway JS, Hübler G, Fehsenfeld FC, Evans MJ. 2002. Trace gas composition of midlatitude cyclones over the western North Atlantic Ocean: a conceptual model. J. Geophys. Res. 107: 4056, DOI: 10.1029/2001JD000901.

Cooper OR, Forster C, Parrish D, Trainer M, Dunlea E, Ryerson T, Hübler G, Fehsenfeld F, Nicks D, Holloway J, Gouw J, Warneke C, Roberts JM, Flocke F, Moody J. 2004. A case study of transpacific warm conveyor belt transport: Influence of merging airstreams on trace gas import to North America. J. Geophy. Res. 109: D23S08, DOI: 10.1029/2003JD003624.

Davis CA, Stoelinga MT, Kuo YH. 1993. The integrated effect of condensation in numerical simulations of extratropical cyclogenesis. Mon. Weather Rev. 121: 2309-2330.

Eckhardt S, Stohl A, Wernli H, James P, Forster C, Spichtinger N. 2004. A 15-year climatology of warm conveyor belts. J. Climate 17: 218-237.

Esler JG, Haynes PH, Law KS, Barjat H, Dewey K, Kent J, Schmitgen S, Brough N. 2003. Transport and mixing between airmasses in cold frontal regions during dynamics and chemistry of frontal zones (DCFZ). J. Geophy. Res. 108: 4142, DOI: 10.1029/2001JD001494.

Flentje H, Dörnbrack A, Ehret G, Fix A, Kiemle C, Poberaj G, Wirth M. 2005. Water vapour heterogeneity related to tropopause folds over the North Atlantic revealed by airborne water vapour differential absorption lidar. J. Geophys. Res. 110: D03115, DOI: 10.1029/2004JD004957.

Flentje H, Dörnbrack A, Fix A, Ehret G, Holm E. 2007. Evaluation of ECMWF water vapour fields by airborne differential absorption lidar measurements: a case study between Brazil and Europe. Atmos. Chem. Phys. 7: 5033-5042. DOI: 10.5194/acp-7-5033-2007.

GLOBE Task Team and others (Hastings DA, Dunbar PK, Elphingstone GM, Bootz M, Murakami H, Maruyama H, Masaharu H, Holland P, Payne J, Bryant NA, Logan TL, Muller JP, Schreier G, MacDonald JS) eds. 1999. The Global Land One-kilometer Base Elevation (GLOBE) Digital Elevation Model, Version 1.0. National Oceanic and Atmospheric Administration, National Geophysical Data Centre, Boulder, CO. Digital data base on the World Wide Web (URL: http://www.ngdc.noaa.gov/mgg/topo/globe.html) and CD-ROMs.

Grams CM, Wernli H, Boettcher M, Campa J, Corsmeier U, Jones SC, Keller JH, Lenz CJ, Wiegand L. 2011. The key role of diabatic processes in modifying the upper-tropospheric waveguide: a North Atlantic case study. Q. J. R. Meteorol. Soc. (submitted).

Hoinka KP, Davies HC. 2007. Upper-tropospheric flow features and the Alps: an overview. Q. J. R. Meteorol. Soc. 133: 847-865.

Kiemle C, Brewer W, Ehret G, Hardesty R, Fix A, Senff C, Wirth M, Poberaj G, LeMone M. 2007. Latent heat flux profiles from collocated airborne water vapour and wind lidars during IHOP_2002. J. Atmos. Oceanic Technol. 24: 627-639.

Knippertz P, Martin JE. 2005. Tropical plumes and extreme precipitation in subtropical and tropical West Africa. Q. J. R. Meteorol. Soc. 131: 2337-2365.

Kuo YH, Shapiro MA, Donall EG. 1991. The interaction between baroclinic and diabatic processes in a numerical simulation of a rapidly intensifying extratropical marine cyclone. Mon. Weather Rev. 119: $368-384$.

Massacand AC, Wernli H, Davies HC. 2001. Influence of upstream diabatic heating upon an alpine event of heavy precipitation. Mon. Weather Rev. 129: 2822-2828.

Pfahl S, Wernli H. 2008. Air parcel trajectory analysis of stable isotopes in water vapour in the eastern Mediterranean. J. Geophys. Res. 113: D20104, DOI: 10.1029/2008JD009839.

Poberaj G, Fix A, Assion A, Wirth M, Kiemle C, Ehret G. 2002. Airborne all-solid-state DIAL for water vapour measurements in the tropopause region: system description and assessment of accuracy. Appl. Phys. 75: 165-172, DOI: 10.1007/s00340-002-0965-x.

Pomroy HR, Thorpe AJ. 2000. The evolution and dynamical role of reduced upper-tropospheric potential vorticity in intensive observing period one of FASTEX. Mon. Weather Rev. 128: 1817-1834.

Prior J, Beswick M. 2008. The exceptional rainfall of 20 July 2007. Weather 63: 261-267.

Rossa AM, Wernli H, Davies HC. 2000. Growth and decay of an extratropical cyclone's PV-tower. Meteorol. Atmos. Phys. 73: 139-156.

Schäfler A, Dörnbrack A, Kiemle C, Rahm S, Wirth M. 2010. Tropospheric water vapour transport as determined from airborne lidar measurements. J. Atmos. Oceanic Technol. 27: 2017-2030.

Sodemann H, Schwierz C, Wernli H. 2008. Inter-annual variability of Greenland winter precipitation sources: Lagrangian moisture 
diagnostic and North Atlantic Oscillation influence, J. Geophys. Res. 113: D03107, DOI: $10.1029 / 2007$ JD008503.

Stohl A, Trickl T. 1999. A textbook example of long-range transport: simultaneous observation of ozone maxima of stratospheric and North American origin in the free troposphere over Europe. J. Geophys. Res. 104: 30445-30462.

Vaughan G, Garland WE, Dewey KJ, Gerbig C. 2003. Aircraft measurements of a warm conveyor belt: a case study. J. Atmos. Chem. 46: 117-129.

Vaughan G, Schiller C, MacKenzie AR, Bower K, Peter T, Schlager H, Harris NRP, May PT. 2008. SCOUTO3/ACTIVE: high-altitude aircraft measurements around deep tropical convection. Bull. Am. Meteor. Soc. 89: 647-662.

Wagner JS, Gohm A, Dörnbrack A, Schäfler A. 2010. The mesoscale structure of a mature polar low: airborne lidar measurements and simulations. Q. J. R. Meteorol. Soc. DOI: 10.1002/qj.857 (in press).

Wakimoto RM, Murphey HV, Browell EV, Ismail S. 2006. The Triple Point on 24 May 2002 during IHOP. Part I. Airborne Doppler and LASE analyses of the frontal boundaries and convection initiation. Mon. Weather Rev. 134: 231-250.

Weckwerth TM, Parsons DB, Koch SE, Moore JA, LeMone MA, Demoz BB, Flamant C, Geerts B, Wang J, Feltz WF. 2004. An overview of the International $\mathrm{H}_{2} \mathrm{O}$ Project (IHOP_2002) and some preliminary highlights. Bull. Am. Meteor. Soc. 85: 253-277.
Weissmann M, Busen R, Dörnbrack A, Rahm S, Reitebuch O. 2005. Targeted observations with an airborne wind lidar. J. Atmos. Oceanic Technol. 22: 1706-1719.

Wernli H. 1997. A lagrangian-based analysis of extratropical cyclones. II. A detailed case-study. Q. J. R. Meteorol. Soc. 123: 467-489.

Wernli H, Davies HC. 1997. A lagrangian-based analysis of extratropical cyclones. I. The method and some applications. Q. J. R. Meteorol. Soc. 123: 1677-1706.

Wirth M, Fix A, Mahnke P, Schwarzer H, Schrandt F, Ehret G. 2009. The airborne multi-wavelength water vapour differential absorption lidar WALES: system design and performance. Appl. Phys. B 63 : 201-213.

Wulfmeyer V, Behrendt A, Bauer HS, Kottmeier C, Corsmeier U, Blyth A, Craig G, Schumann U, Hagen M, Crewell S, Di Girolamo P, Flamant C, Miller M, Montani A Mobbs S, Richard E, Rotach MW, Arpagaus M, Russchenberg H, Schlüssel P, König M, Gärtner V, Steinacker R, Dorninger M, Turner DD, Weckwerth T, Hense A, Simmer C. 2008 The convective and orographically-induced precipitation study: a research and development project of the World Weather Research Program for improving quantitative precipitation forecasting in lowmountain regions. Bull. Am. Meteor. Soc. 89: 1477-1486.

Ziv B, Saaroni H, Romem M, Heifetz E, Harnik N, Baharad A. 2010. Analysis of conveyor belts in winter Mediterranean cyclones. Theor. Appl. Climatol. 99: 441-455. 